\title{
INFLUÊNCIAS DO PIBID/SUBPROJETO INTERDISCIPLINAR NA ESCOLHA DE ATUAÇÃO PROFISSIONAL DO PEDAGOGO
}

\section{INFLUENCES OF THE PIBID / INTERDISCIPLINARY SUBPROJECT IN THE CHOICE OF PROFESSIONAL ACTIVITY OF THE PEDAGOGUE}

\author{
Priscila da Silva Rocha ${ }^{1}$ \\ Ricardo Luiz de Bittencourt ${ }^{2}$
}

\begin{abstract}
RESUMO: Esse artigo pretende analisar como a participação no Programa Institucional de Bolsas de Iniciação à Docência (Pibid) pode influenciar na escolha do campo de atuação profissional do acadêmico de Pedagogia. O contato dos pedagogos com as áreas em que é possível atuar acontece dentro e fora da universidade, essencialmente nas escolas, através do estágio obrigatório ou não obrigatório, e também em projetos institucionais como o Pibid. Essa escolha e a preferência do campo profissional pode ser justificada nas experiências proporcionadas ao acadêmico durante a graduação como sugere a pesquisa. Autores como Nóvoa (1992/2009), Tardif (2000/2002) e García (1999) embasam as reflexões sobre a formação docente, principalmente construída dentro da própria profissão. Os objetivos específicos se definiram em responder a importância do Pibid na formação inicial, quais as contribuições do curso de Magistério para a formação do pedagogo e investigar como acontece a escolha da área de atuação do pedagogo. A pesquisa questionou cinco acadêmicos de diferentes fases do curso de Pedagogia, que foram bolsistas do Pibid Subprojeto Interdisciplinar no curso de Magistério. $\mathrm{O}$ estudo apontou que a participação neste programa influencia na escolha da área de atuação porque permite ao acadêmico vivenciar experiências da realidade escolar, e também por ser uma proposta desenvolvida em um curso de formação de professores.
\end{abstract}

PALAVRAS CHAVE: Pedagogia. Pibid. Formação de professores.

ABSTRACT: This article intends to analyze how participation in the Institutional Program of Teaching Initiation Scholarships (Pibid) can influence the choice of the field of professional performance of the academic. The contact with the areas in which it is possible to act happens inside and outside the university, essentially in the schools, through the obligatory or noncompulsory internship, and also in institutional projects like Pibid. This choice and the preference of the professional field can be justified in the experiences provided to the academic during the undergraduate study as the research suggests. Authors such as Nóvoa (1992/2009), Tardif (2000/2002) and García (1999) base the reflections on teacher education, mainly built within the profession itself. The specific objectives were defined in answering

\footnotetext{
${ }^{1}$ Acadêmica do curso de Pedagogia/ UNESC. priscilarocha16@ hotmail.com

${ }^{2}$ Orientador. Graduado em Pedagogia. Doutor em Educação. rlb@unesc.net.

Saberes Pedagógicos, Criciúma, v. 3, n³, Edição Especial 2019.- Curso de Pedagogia - UNESC
} 


\section{SABERES PEDAGÓGICOS}

Revista do Curso de Graduaçāo de Pedagogia - Unesc

ISSN 2526-4559

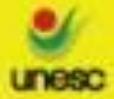

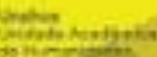

the importance of the Pibid in the initial formation, what the contributions of the Magisterium course for the formation of the pedagogue and investigate how it happens the choice of the area of action of the pedagogue. The research questioned five academics from different periods of Education who were scholarship holders of the Pibid Institutional Program of Teaching Initiation Scholarships. The study pointed out that participation in this program influences the choice of field of work because it allows the academic to experience the school reality, and also because it is a proposal developed in a teacher training course.

KEYWORDS: Pedagogy. Pibid. Teacher training.

\section{INTRODUÇÃO}

$\mathrm{O}$ curso de Pedagogia tem aberto um leque de possibilidades quanto às áreas de atuação profissional, que se estende da Educação Básica como professor da primeira infância na Educação Infantil e Ensino Fundamental anos iniciais, até os espaços extraescolares como a Pedagogia Empresarial e a Pedagogia Hospitalar. Neste sentido, as experiências proporcionadas pela universidade enquanto formadora, têm contribuído para que se conheçam os ambientes em que o pedagogo poderá exercer seu trabalho.

Quanto à participação nos espaços escolares, o estágio obrigatório e não obrigatório tem oportunizado a todos os acadêmicos esse contato com a formação construída no exercício da profissão. Paralelo a essa formação, vemos no âmbito das políticas públicas projetos institucionais desenvolvidos em universidades e financiados pelo Governo, que também tem contribuído para a formação inicial e continuada dos professores, como é o Pibid (Programa Institucional de Bolsas de Iniciação à Docência).

Estudos já têm mostrado que o programa tem sido um incentivador à formação docente, pois aproxima a universidade à realidade escolar, proporcionando ao acadêmico bolsista a experiência de ser um professor de forma assistida. A proposta também tem proporcionado a reflexão sobre teoria e prática, por meio dos planejamentos e encontros semanais nos quais se apresentam os resultados obtidos em sala. Com a supervisão de professores universitários e professores da Educação Básica, o projeto vai gerando novos conhecimentos, enquanto integra Educação Básica e Educação Superior.

Buscando desenvolver uma pesquisa relevante para o curso de Pedagogia e que pudesse expressar as contribuições do programa para minha formação inicial na condição de 
bolsista, a pesquisa se definiu em responder qual a influência do Pibid, Subprojeto Interdisciplinar, sobre a escolha da área de atuação do pedagogo, destacando que o estudo foi realizado com acadêmicos que atuaram no Curso de Magistério. Os objetivos específicos foram direcionados a identificar a importância do Pibid na formação inicial, pesquisar as contribuições do curso de Magistério para a formação do pedagogo e investigar como acontece a escolha da área de atuação do pedagogo. Pesquisando sobre artigos existentes no curso direcionados a essa temática, foi encontrada uma pesquisa realizada com acadêmicos da área de Pedagogia sobre a escolha de atuação profissional de forma geral, diferindo da presente pesquisa que está direcionada à participação no Pibid como indutor nessa escolha.

Deste modo, o artigo se divide em duas seções. A primeira "A Profissão docente no contexto da Pedagogia" aborda de forma breve a trajetória do curso no Brasil, trazendo questões da formação de professores e os desafios inerentes à profissão. A segunda seção "Pibid e a formação inicial de professores" aborda as contribuições do programa para a formação inicial e como é desenvolvido nas escolas, também discorre sobre o curso de Magistério onde os bolsistas atuaram e que habilita professores para Educação Infantil e anos iniciais do Ensino Fundamental.

\section{A PROFISSÃO DOCENTE NO CONTEXTO DA PEDAGOGIA}

Conforme as Diretrizes Curriculares Nacionais para o Curso de Graduação em Pedagogia (BRASIL, 2006) o curso consiste em formar profissionais aptos para o exercício do magistério, na Educação Infantil, anos iniciais do Ensino Fundamental, disciplinas do Ensino Médio no curso de Magistério, Educação de Jovens e Adultos (alfabetização), apoio na Gestão Escolar, e outras áreas vinculadas ao ensino e que prevejam conhecimentos pedagógicos, como na Pedagogia Empresarial e a Pedagogia Hospitalar. É importante ressaltar que o Curso supracitado não habilita somente professores, contudo, o enfoque dessa pesquisa está na formação docente dos profissionais pedagogos.

A palavra Pedagogia originalmente vem do grego como paidagogos e nomeava o escravo que conduzia a criança do seu senhor em atividades cotidianas e em situações de aprendizagem. Com o passar do tempo, a palavra foi tomando novos sentidos, esboçando a 


\section{SABERES PEDAGÓGICOS}

Revista do Curso de Graduaçāo de Pedagogia - Unesc

ISSN 2526-4559

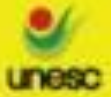

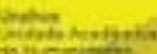

ideia do ensino aprendizagem (ação pedagógica) e ampliando o significado do ser docente (ARANHA, 2006).

Contudo, nem sempre o ato de ensinar e a profissão docente foram reconhecidos como inerentes ao professor. A educação passou por vários períodos, marcada, em cada um deles, por uma forma diferente de pensar e de ensinar. Sabe-se que a educação no Brasil sofreu forte influência da religião, consolidando um formato religioso de ensino que tinha como objetivo a doutrinação do homem.

Conforme Aranha (2006) o renascimento iniciado no século XIV foi um marco do interesse pela educação e pela busca do conhecimento e, assim, seguiu até os primeiros colégios jesuítas, que vieram para o Brasil com os colonizadores, influenciando e moldando a educação brasileira. Eram os padres jesuítas que ensinavam a ler e escrever, ao mesmo tempo em que catequizavam. Esse formato de ensino perdurou até o Iluminismo (XVIII), quando se entendeu que a escola deveria ser laica e livre, sugerindo uma reforma na educação.

A partir desse momento, é que a formação de professores passou a ter mais visibilidade, surgindo no Brasil as primeiras universidades. Sobre a formação de professores, García (1999) ressalta que essa deve propiciar o contexto para o desenvolvimento intelectual, social e emocional dos educadores e, também, que essa formação os tornem capazes de transformar o conhecimento do conteúdo em conhecimento de como ensinar.

Assim, a Pedagogia, hoje, expressa a prática e a profissão docente, entendendo o ato de ensinar como específico do professor, no sentido pedagógico, pois há intencionalidade, e essa está a serviço do processo de ensino aprendizagem. Segundo García (1999), qualquer um pode ensinar, mas isso não é o mesmo que ser um professor.

Para tanto, a formação de professores também exige que haja unidade no processo formativo de modo que se possa ressignificar a teoria à medida que se realiza a prática, como aborda Libâneo (2015, p. 21):

[...] um sistema de formação de professores precisa buscar uma unidade no processo formativo que assegure relações teóricas e práticas mais sólidas entre a didática e a epistemologia das ciências, rompendo com a separação e o paralelismo entre conhecimentos disciplinares e conhecimentos pedagógicos-didáticos. 
Neste sentido, a formação de professores sugere que a teoria possa promover práticas mais sólidas, de modo que o conhecimento acadêmico possa ganhar sentido ao mesmo tempo em que é aplicado. Assim, vai se superando a distância entre as disciplinas e os próprios métodos pedagógico-didáticos aprendidos na universidade.

Nóvoa (2009) enfatiza que ser professor é compreender a instituição escolar, aprendendo com os colegas e suas experiências, pois na escola e no contato com os demais professores é que vai se aprendendo a profissão e se construindo o conhecimento profissional docente. Portanto, é no contexto escolar e na interação com os outros que vão surgindo às situações cotidianas e inerentes à escola, nas quais o professor começa a ter contato com a realidade, construindo o saber docente, não somente de teorias, mas também de suas experiências.

Tardif (2002) ressalta que o professor em seu trabalho traz sua cultura pessoal, sua cultura escolar e os conhecimentos adquiridos na universidade, mas ele também se apoia nas suas próprias experiências, nas dos colegas e nos conhecimentos oriundos dos programas, guias e manuais escolares. Desse modo, fica explícito que a identidade do professor é construída dentro da universidade e também na escola. $\mathrm{O}$ conhecimento universitário vai sendo ressignificado com a prática e na reflexão do seu trabalho, que vai exigindo respostas.

Percebemos que na escola essa ressignificação do conhecimento acontece no contato com outros professores e com os alunos também. Ambos autores abordam que o contato com a realidade escolar vai construindo a identidade do professor e definindo sua prática pedagógica. Esta por sua vez vai se moldando a partir da realidade em que o professor está inserido, ou seja, o ser professor se define em uma construção diária, é um ser inacabado, visto que o conhecimento é infinito também.

Quanto aos primeiros contatos com a realidade escolar, as universidades têm articulado os estágios obrigatórios que permitem um breve contato do acadêmico com exercício docente. No estágio obrigatório o acadêmico escolhe uma turma para observar (conforme a modalidade de ensino exigida) e sob a supervisão e acompanhamento de um professor da universidade ele irá elaborar um projeto ou plano de aula e aplicá-lo na turma escolhida. No término do estágio é realizada a socialização das atividades e do seu trabalho 
gerando uma nota avaliativa estabelecidas pelos professores supervisor e regente que determinará a aprovação na disciplina de estágio.

Para Tardif (2000) esse modelo de formação se caracteriza como aplicacionista, pois os alunos passam parte do seu tempo em sala de aula aprendendo e incorporando conteúdos que durante os estágios deverão ser aplicados. No modelo supracitado o conhecer e o fazer acontecem separadamente, o que acaba desvirtuando o conhecimento que deveria ser construído na prática.

Há também o estágio não obrigatório, que diferencia-se do obrigatório por proporcionar ao acadêmico o contato com a profissão desde a primeira fase, mas sem as responsabilidades de observar e planejar as aulas, e também sem nota avaliativa. Além disso, o acadêmico ganha uma bolsa auxílio que muitas vezes o ajuda a custear despesas do curso.

Esse formato de formação permite um maior tempo de observação e o contato diário com professores e alunos. Contudo, no estágio não obrigatório o acadêmico fica restrito a auxiliar e cuidar dos alunos, distanciando-se do planejamento das atividades e da responsabilidade de responder pela turma. Nessa direção é possível inferir que as múltiplas experiências que o estudante de Pedagogia vai construindo ao longo de sua formação contribuirá para ajudá-lo a escolher o campo de atuação profissional.

Nóvoa (2009) aborda que a formação deve colaborar no sentido de criar hábitos de reflexão e autorreflexão a partir de referências pessoais, que deve ser construída na observação de outras práticas, mas também na reflexão do próprio trabalho. O objetivo de utilizar a escola então como espaço de formação é valorizar a experiência coletiva, a partir das experiências individuais.

Neste contexto de necessidade de inovação na formação docente surge o Pibid, oriundo de políticas públicas do Governo Federal em escolas públicas de educação básica, como proposta diferente dos estágios, obrigatório e não obrigatório. Este projeto foi concebido numa perspectiva de valorizar a formação inicial dos acadêmicos de licenciaturas, ou seja, futuros professores. 


\section{SABERES PEDAGÓGICOS}

Revista do Curso de Graduaçāo de Pedagogia - Unesc

ISSN 2526-4559

\subsection{Pibid e a formação de professores}

O Pibid é um programa ofertado a acadêmicos das licenciaturas em cursos presenciais, que vem ao encontro da formação docente. A proposta promove a articulação entre teoria e prática e também tem aproximado a universidade das escolas públicas, assegurando a formação inicial dos novos professores, mas também a formação continuada daqueles que já atuam na Educação Básica.

Conforme o Decreto $\mathrm{n}^{\mathrm{o}} 7219 / 2010$, o Pibid, sob responsabilidade da Capes (Coordenação de Aperfeiçoamento de Pessoal de Nível Superior), tem como finalidade promover a iniciação à docência, colaborando para o aprimoramento da formação de professores em nível superior e para a melhoria e qualidade da educação básica pública brasileira, instituído e financiado pelo Governo Federal (BRASIL, 2010).

Deste modo, o programa tem contribuído com a formação docente por aproximar o conhecimento profissional e o conhecimento acadêmico, dentro do contexto escolar. O trabalho dos professores mais experientes junto ao do novo professor, sugere que a aprendizagem gere reflexão, surgindo novos conhecimentos, não somente teóricos, mas da realidade diária. A proposta também vem ao encontro da valorização das políticas públicas, por ser um programa que almeja aproximar as universidades das escolas de Educação Básica.

O contato do acadêmico com a escola, desde o início da graduação, possibilita um olhar mais amplo da profissão e também a interação entre teoria e prática. Sobre a formação de professores no sentido pessoal e profissional, Nóvoa (1992) traz reflexões sobre as dimensões que o professor é sujeito. Para ele, a atividade educativa não é previsível e está sujeita as dimensões pessoais, e ao mesmo tempo profissionais que surgem no dia a dia.

Neste sentido, o ensino do ser docente passa a ser construído dentro da própria profissão, uma vez que o contexto escolar "exige que tenhamos a capacidade de recontextualizar a escola no seu lugar próprio, valorizando aquilo que é especificamente escolar." (NÓVOA, 2009, p. 8).

O Pibid, por sua vez, tem sido esse recontextualizador da escola, e a sala de aula um espaço de formação rica para acadêmicos e também para os professores, tanto supervisores (escola), quanto os coordenadores (universidade). Essa inserção no contexto Saberes Pedagógicos, Criciúma, v. 3, nº3, Edição Especial 2019.- Curso de Pedagogia - UNESC 
escolar dá sentido à teoria aprendida na universidade e possibilita à reflexão das práticas pedagógicas adotadas pelo professor e pelos próprios acadêmicos A participação no programa também tem sido um espaço de compartilhar experiências, pois os professores supervisores desses acadêmicos em formação abrem seu espaço de trabalho para que ocorra uma nova aprendizagem oriunda deste projeto.

\begin{abstract}
Se o Programa é interessante para os graduandos, também o é para os professores supervisores que se beneficiam dessa troca de experiências que implica um repensar da prática docente. Significa, literalmente, a inserção de "sangue novo" pela promoção do trabalho em equipe, contribuindo para o crescimento pessoal e profissional pelo repensar a prática escolar, superando uma tendência de reprodução de práticas consolidadas de forma acrítica. Também as Instituições de Ensino Superior saem ganhando, ao serem convidadas a pensar seus processos de formação. (SOCZEK, 2011, p. 8).
\end{abstract}

As instituições de formação docente possuem a responsabilidade de aproximar o conhecimento universitário da prática profissional e, essa articulação, visa à construção de novos conhecimentos.

[...] o conhecimento da prática profissional e o conhecimento acadêmico podem se relacionar de forma menos hierárquica e mais igualitária, favorecendo, assim, a transformação e a construção de um novo conhecimento. [...] A aprendizagem da docência se desenvolve melhor quando futuros professores trabalham de perto com professores experientes e com alunos para experimentar o que eles estão aprendendo. (AMBROSETTI, 2013, p. 156).

Sendo assim, o Pibid tem desenvolvido um importante papel na universidade. É notável a movimentação que o programa traz à instituição, principalmente em eventos e nos artigos redigidos por professores e acadêmicos ao relatarem suas experiências e, também, resultado da reflexão entre teoria e prática que esse trabalho proporciona. Cada licenciatura possui os subprojetos e algumas trabalham em conjunto, como acontece no Subprojeto Interdisciplinar.

Quanto à participação no Subprojeto Interdisciplinar, que foi o alvo dessa pesquisa, o foco esteve em trabalhar novas metodologias que possibilitassem um planejamento e execução do projeto na perspectiva da interdisciplinaridade. A inserção dos acadêmicos no curso de Magistério oportunizou a efetivação deste trabalho, bem como a 
experiência de ser professor, elaborando projetos e fazendo planejamentos desenvolvidos em sala de aula com futuros professores.

O curso de magistério caracteriza-se como um curso de nível médio e diferenciase do curso de formação geral por oportunizar aos estudantes uma formação profissional. $\mathrm{O}$ magistério, então, traz uma realidade nova às bolsistas do Pibid, principalmente por oportunizar o trabalho com adultos e também por ser um curso de formação de professores.

De acordo com as Diretrizes Curriculares Nacionais para a formação de Professores na Modalidade Normal em Nível Médio (BRASIL, 1999), a finalidade do Curso de Magistério é habilitar professores para a Educação Infantil e anos iniciais do Ensino Fundamental, e que esse ensino seja comprometido com a qualidade da educação pública, ofertada a crianças, jovens e adultos.

O Curso possui disciplinas de fundamentos da educação, metodologias de ensino e estágio. A participação dos bolsistas pesquisados se deu na disciplina de Fundamentos e Metodologias da Alfabetização e Letramento bem como Fundamentos e Metodologia da Língua Portuguesa, e contribuiu muito para a formação inicial dos acadêmicos, visto que uma das atribuições dos professores formados em Pedagogia está no ensino da língua escrita, através do processo de alfabetização e letramento.

Do ponto de vista formativo, o Pibid tem sido um bom modelo de formação docente, tanto inicial quanto continuada, pois ele não descarta os conhecimentos da sala de aula, nem tampouco os conhecimentos teóricos, mas à medida que surgem as necessidades, esses conhecimentos se renovam contribuindo com todos os envolvidos no processo de ensino aprendizagem.

\section{METODOLOGIA, APRESENTAÇÃO E ANÁLISE DE DADOS}

Essa pesquisa se caracteriza como pesquisa explicativa, pois conforme Gil (2008) este tipo de análise tem interesse em reconhecer as causas que contribuem ou que são determinantes para a ocorrência dos fenômenos que serão investigados.

O objetivo da pesquisa foi analisar as influências do Pibid/Subprojeto Interdisciplinar na escolha de atuação profissional do pedagogo. Para isso, a investigação Saberes Pedagógicos, Criciúma, v. 3, nº3, Edição Especial 2019.- Curso de Pedagogia - UNESC 


\section{SABERES PEDAGÓGICOS}

Revista do Curso de Graduaçāo de Pedagogia - Unesc

ISSN $2526-4559$

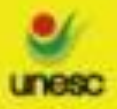

7xitivengen

realizada foi de natureza básica, em uma abordagem qualitativa, buscando responder as indagações em que se originou o problema. Conforme Pinheiro (2010, p. 20), a pesquisa em caráter qualitativo "[...] caracteriza-se pela tentativa de uma compreensão detalhada dos significados e características situacionais apresentadas pelos entrevistados [...].” Assim, durante a pesquisa devem aparecer particularidades em opiniões dos entrevistados sobre o tema estudado.

A escolha dos acadêmicos participantes dessa pesquisa se deu pelo tempo em que participaram do Pibid, por serem do curso de Pedagogia e também por terem permanecido até o encerramento do programa. Foram eles, cinco acadêmicos, que atuaram no Subprojeto Interdisciplinar no curso de Magistério de uma escola de Criciúma, SC. Esta foi realizada em campo, sendo o local escolhido para as entrevistas, a universidade. $\mathrm{O}$ instrumento para coleta de dados foi entrevista semiestruturada com um roteiro contendo nove perguntas abertas. A fim de preservar a identidade dos acadêmicos entrevistados, serão utilizados nomes fictícios, identificando-os como: Artur, Bruna, Caroline, Daniela, Ester.

As entrevistas foram realizadas durante duas semanas no mês de Maio de 2018 e gravadas em câmera digital, sendo posteriormente transcritas, resultando em 10 páginas. As informações foram organizadas em três seções: Sobre os sujeitos da pesquisa; Contribuições do Pibid para a formação inicial; Influências do Pibid na escolha da área de atuação. Os entrevistados assinaram o termo de consentimento que está em posse da pesquisadora.

\subsection{Sobre os sujeitos da pesquisa}

Dos cinco entrevistados, quatro são do sexo feminino, e um, do masculino. Duas acadêmicas relataram não ter realizado estágio obrigatório no Magistério, dois realizaram durante o tempo em que atuaram no Pibid, e um, posterior à participação no programa.

Sobre a fase em que cursam e o tempo de permanência no Pibid/Subprojeto Interdisciplinar no Curso de Magistério, os entrevistados responderam: Artur, $8^{\mathrm{a}}$ fase, tempo de atuação: 3 semestres; Bruna, $6^{\mathbf{a}}$ fase, tempo de atuação: 1 semestre; Caroline, $6^{\mathbf{a}}$ fase, tempo de atuação: 1 semestre e meio; Daniela, $8^{\text {a }}$ fase, tempo de atuação: 2 semestres; Ester, $6^{\mathrm{a}}$ fase, tempo de atuação: 1 semestre.

Saberes Pedagógicos, Criciúma, v. 3, n³, Edição Especial 2019.- Curso de Pedagogia - UNESC 
A disciplina em que atuaram foi: Fundamentos e Metodologia da Alfabetização e Letramento e Fundamentos e Metodologia da Língua Portuguesa. Os projetos desenvolvidos foram: o ensino da elaboração de um plano de aula, projetos sobre literatura com ênfase na alfabetização e letramento e também projeto de musicalização. Os temas foram em consenso com professores e alunas, visando atender as necessidades da turma.

\subsection{Contribuições do Pibid para a formação inicial}

Nesta seção buscou-se investigar quais as contribuições que o programa oferece aos acadêmicos que estão em processo de formação inicial, tendo em vista que essas experiências podem influenciar de forma positiva na escolha do campo de atuação, já que o Pibid proporciona um contato mais prolongado com a realidade escolar.

Quando questionados sobre o primeiro contato com a escola na condição de bolsistas, os acadêmicos Bruna, Daniela, Ester relatam ter sido bem recepcionados e que o primeiro contato com a escola foi muito bom. Daniela ainda acrescenta, que isso pode se dar ao fato de o projeto já ser conhecido na escola, por alunos e professores. Artur e Caroline afirmam que o primeiro contato foi com receio e que traz um choque de realidade, principalmente por estarem trabalhando com adultos, como pode se observar em suas falas:

\footnotetext{
No primeiro momento nos faz ter um choque de realidade que nos remete a condição de professor em formação e ao decorrer do tempo nos faz ter um novo olhar para a sala de aula, além do fato da nossa preparação como professor. (ARTUR)

A recepção na escola foi muito boa, o coordenador da escola era muito atencioso, enfim foi bem legal. (BRUNA)

O meu primeiro contato com a escola na condição de pibidiana foi com bastante receio, tentando quebrar barreira, por ser o magistério, por já estar indo ter contato diretamente com adulto [...]. (CAROLINE)

$\mathrm{O}$ primeiro contato com as escola foi muito bom, foi bem tranquilo, eu acredito que porque na escola que eu e minha dupla fomos fazer o Pibid nós fomos muito bem recebidas por esse projeto já ter andamento na escola, então os alunos já tinham conhecimento desse projeto, o professor já era participante desse projeto, então fomos bem recebidas porque todos já tinham conhecimento do que era o Pibid. (DANIELA)

Referente ao meu primeiro contato como pibidiana na escola foi muito bom, acredito que um dos motivos era por eu ser ex aluna, os professores me receberam de outra forma, mas tanto o coordenador do magistério, como os acadêmicos, como os professores do magistério me receberam muito bem e eu acho que foi um contato bem bom, em todas as escolas foi bom, mas eu acho que teve minha parte mesmo com um melhor aproveitamento. (ESTER)
}

Saberes Pedagógicos, Criciúma, v. 3, n³, Edição Especial 2019.- Curso de Pedagogia - UNESC 


\section{SABERES PEDAGÓGICOS}

Revista do Curso de Graduaçāo de Pedagogia - Unesc

ISSN 2526-4559

Levando em consideração que o retorno ao espaço escolar causa um choque de realidade como afirma o entrevistado, é normal e aceitável essa reação, pois agora os acadêmicos se deparam com os desafios da profissão. Embora tenham o acompanhamento dos professores, eles se sentem participantes no processo de ensino aprendizagem desses alunos, e mais do que isso, se sentem responsáveis pelos erros e acertos que obterão durante o desenvolvimento do projeto.

Conforme Ambrosetti (2013), esse contato inicial dos acadêmicos com a escola causa um estranhamento, visto que muitos, agora, estão retornando a um espaço que já frequentaram na condição de alunos, por outro lado carregam uma nova bagagem de conhecimento, a teoria aprendida na universidade:

[...] é o estranhamento inicial no encontro de instituições com culturas e conhecimentos muito diferentes. Segundo os estudantes, o ingresso na escola pública - para muitos deles um universo desconhecido e cercado por preconceitos é um momento ao mesmo tempo de tensão e curiosidade. Mesmo para os participantes que cursaram escolas públicas, o retorno a esse espaço, agora com o olhar informado pelas teorias acadêmicas, é um momento de redescoberta [...]. (AMBROSETTI, 2013, p. 162).

Interrogados sobre a realização do estágio obrigatório, Artur, Daniela e Ester afirmam já terem concluído essa etapa, e consideram que o Pibid foi muito importante para que obtivessem êxito nessa modalidade. Artur reitera que "a atuação e preparação das aulas foi mais fácil e reflexiva, pois no Pibid aprendemos que no Magistério, os professores, assim como nós, eram futuros docentes em formação". Para Daniela, "tendo a experiência anterior como bolsista do Pibid foi muito mais tranquilo porque eu já conhecia o público, a logística do magistério, já conhecia alguns professores [...], me senti supersegura para aplicar o nosso plano de estágio". Ester "comecei no mesmo semestre o estágio obrigatório e foi muito melhor [...], se não fosse eu estar no Pibid, acho que o desenvolvimento não seria tão bom."

As entrevistadas, Bruna e Caroline, dizem não ter realizado estágio obrigatório ainda, mas afirmam se sentirem seguras, "eu me sinto superpreparada, não tenho medo nenhum" afirma Caroline. Bruna completa "não realizei estágio obrigatório, e sim, me sinto preparada, porque o Pibid me deu oportunidade de ter o contato com a prática, não só a teoria."

Saberes Pedagógicos, Criciúma, v. 3, n³, Edição Especial 2019.- Curso de Pedagogia - UNESC 
A fala dos acadêmicos vem ao encontro do que afirma Nóvoa $(2009$, p. 6) "nestes anos em que transitamos de aluno para professor é fundamental consolidar as bases de uma formação que tenha como referência lógicas de acompanhamento, de formação em situação, de análise da prática e de integração na cultura profissional docente."

Deste modo, participar de uma proposta que promove a formação e o contato com a profissão, proporciona mais segurança ao graduando, tendo em vista, que este é colocado frente à situações reais e o mais importante, ele vem sendo acompanhado por outros professores.

Quando questionados sobre a importância do programa para a formação inicial, todos responderam que consideram "muito importante". Artur acrescenta que, "pelo Pibid conseguimos pensar em cada ação a ser tomada”. Bruna cita a realidade escolar em que é inserida "a gente não fica só dentro da sala de aula na teoria, a gente vai pra realidade, a gente vai pra prática", Caroline aponta que "minha formação não teria sido igual se não tivesse passado esses nove meses no Pibid. Ester e Daniela "fundamental, essencial, na formação do acadêmico."

As respostas dos acadêmicos confirmam o que a autora aborda sobre a inserção dos acadêmicos nos espaços escolares e as dimensões que esse movimento suscita:

\footnotetext{
A partir da inserção no espaço escolar os alunos levam para as salas de aula das universidades as questões do cotidiano docente, promovendo o diálogo entre a dimensão teórica e prática da formação e um novo olhar para os conhecimentos teóricos, agora submetidos à releitura pelo filtro da prática [...]. (AMBROSETTI, 2013, p. 166).
}

Assim, as experiências que os acadêmicos agora trazem para a sala de aula ressignificam os conhecimentos que a universidade oferece, uma vez que a teoria e a prática devem caminhar juntas, mas precisam ser compreendidas em suas especificidades.

Indagados sobre a contribuição das experiências do Pibid no curso de Magistério para a própria formação, cada um aponta um dos benefícios que o projeto trouxe:

A questão do domínio nas argumentações, firmeza nas tomadas de atitudes e decisões e empatia para com o outro. (ARTUR)

Saberes Pedagógicos, Criciúma, v. 3, n³, Edição Especial 2019.- Curso de Pedagogia - UNESC 
As leituras que o coordenador propõe, o aprender a fazer um plano de aula, um artigo... é muito importante, até porque pra preparação pra aprender a fazer um TCC. (BRUNA)

Então, pensando pelo lado acadêmico e também já no profissional, o Pibid me proporcionou como formação inicial, poder ver a educação por outro ângulo, de forma que eu não tivesse medo de entrar na sala de aula com pessoas adultas. A minha formação não teria sido a mesma se eu não tivesse passado pelo programa [...]. No magistério já foi diferenciado também por estar tendo contato com outra formação de professores, é um diferencial muito grande. (CAROLINE)

Pra mim o Pibid no curso de magistério contribui pra minha formação, primeiro porque eu tive a experiência nessa modalidade de ensino que foi o magistério [...] $\mathrm{E}$ agora eu tenho maior segurança se vier essa necessidade de trabalhar com magistério, eu me sinto segura, porque eu já conheço o público, conheço a logística das aulas. (DANIELA)

As experiências são as melhores, é uma área que eu gostei. E trabalhar com adultos é diferente, de trabalhar na EJA e no magistério, isso eu percebi de que tu está formando um profissional, tu é uma pedagoga que está formando profissional [...]. (ESTER)

O destaque que cada um dá a contribuição que o Pibid lhe trouxe, encontra amparo teórico em Nóvoa (2009, p. 6), que destaca a importância de “[...] devolver a formação de professores aos professores, porque o reforço de processos de formação baseadas na investigação só faz sentido se eles forem construídos dentro da profissão [...]”, ou seja, a proposta tem colaborado no sentido de propiciar a construção de novos conhecimentos dentro da profissão e também porque tem inserido os acadêmicos em um espaço de formação docente.

A participação no programa gerou artigos e participações em eventos, ao serem interrogados sobre a importância dessas produções, os bolsistas classificam como muito importante. Artur expõe, "se tornava mais significativo, pois era preciso mostrar o que se produziu durante o semestre". Para Bruna a importância esteve em "conhecer autores, que na graduação não vimos", Caroline completa que se sentiu importante porque "no dia do evento que tinha a banca que estava avaliando, [...] as meninas da banca fizeram bastante perguntas e eu consegui responder todas". Para Daniela a contribuição dessas experiências reside no sentido de ser "necessário que o professor se sinta à vontade de estar na frente na sala de aula, de estar apresentando um trabalho e estar fazendo pesquisa". Ester reitera que "acrescentou no meu currículo de acadêmica".

Para Soczek (2011) existem espaços ainda não preenchidos na formação que levam os futuros professores à insegurança ao apresentar conteúdos e, muitas vezes, a falta de Saberes Pedagógicos, Criciúma, v. 3, nº3, Edição Especial 2019.- Curso de Pedagogia - UNESC 
habilidade de falar em público também se torna um peso nesse processo. Através do Pibid tem se percebido um aumento na participação e publicações dos acadêmicos em eventos, que traz um diferencial à essa formação no sentido de maior qualificação desses sujeitos.

\subsection{Influências do Pibid na escolha da área de atuação}

Até aqui, tem ficado explícitas as contribuições do Pibid para a formação de professores, principalmente a inicial. A partir disso, buscou-se analisar se essa participação gera influências na escolha do acadêmico pelo campo de atuação.

Buscando entender a preferência dos acadêmicos pela área de atuação, foi questionado sobre o trabalho com crianças e adultos, qual dava mais satisfação a eles e qual a área de atuação pretendiam escolher. Constatou-se que, Bruna e Caroline preferem o trabalho com crianças (Educação Infantil), Artur e Daniela preferem o trabalho com adultos (Magistério, EJA e Gestão Escolar). Ester respondeu achar difícil diferenciar o trabalho com ambos e completa "eu quero ir pra espaços diferenciados, eu quero levar minha Pedagogia pra outros lados, ou trabalhando na área de deficiência, ou numa brinquedoteca, espaço lúdico."

A fim de responder essa seção e o problema que norteou essa pesquisa, os bolsistas foram questionados se consideram que o programa exerce influência na escolha do campo profissional, todos entrevistados responderam que sim. Então pediu-se que essa resposta fosse justificada.

De alguma forma tem influência pois por meio do programa podemos nos encontrar como um profissional em formação, atuando desde a Educação Infantil até o Magistério. (ARTUR)

Sim, porque ele deu uma visão importante pra afirmar a área que eu sempre desejei trabalhar que foi desde o início da graduação, a Educação Infantil. Então ele só me deu a certeza que é isso que eu quero. (BRUNA)

Acredito que o Pibid tem muita influência, vou justificar minha resposta. Eu me formei quero muito passar no concurso do Estado porque eu quero dar aula no magistério, alguém me pergunta por que tu quer dar aula no magistério? Porque eu já tive contato eu já sei como funciona, então gostei muito. Talvez se eu não tivesse participado do Pibid eu temeria em ir. Eu teria um certo medo, porque eu professora formada vou formar outros professores, isso gera um certo medo, então por já ser bolsista do Pibid eu não tenho e acredito que influencia muito sim na hora de escolher. (CAROLINE)

Eu acredito que o Pibid pode influenciar a escolha de atuação da área do pedagogo, mas no meu caso eu tive uma experiência muito boa com o magistério, eu tenho

Saberes Pedagógicos, Criciúma, v. 3, n³ 3, Edição Especial 2019.- Curso de Pedagogia - UNESC 
preferência nos adultos se comparado com as crianças, acredito que isso influencie nesse sentido. Quando a experiência com o Pibid é positiva o pedagogo quando formado tende a escolher algo que ele já tenha experimentado, que tenha sido positivo pra ele. (DANIELA)

Acredito que no Pibid tu consegue ter mais contato com algumas áreas, que no nosso caso foi o interdisciplinar, do que só o estágio obrigatório. Então acho que o Pibid foi de extrema importância, querendo ou não, sim influenciando, fazendo com que o acadêmico conheça novos espaços conheça novas oportunidades de atuação, no nosso caso dentro da Pedagogia. (ESTER)

De acordo com Tardif (2000), é necessário um entendimento mais profundo da formação de professores, tendo em vista que esse conhecimento deva se basear nos próprios professores, para que se possa entender suas práticas, sua identidade e, até mesmo, suas escolhas

O trabalho não é primeiro um objeto que se olha, mas uma atividade que se faz, e é realizando-a que os saberes são mobilizados e construídos. Esse enfoque considera que o profissional, sua prática e seus saberes não são entidades separadas, mas "copertencem" a uma situação de trabalho na qual "coevoluem" e se transformam. Querer estudar os saberes profissionais sem associá-los a uma situação de ensino, a práticas de ensino e a um professor seria, então, um absurdo. (TARDIF, 2000, p. 7).

Para Soczek (2011, p. 6) a participação no Pibid vem "fornecer um tempo de reflexão sobre a assunção efetiva das responsabilidades de sua condição de professor", ou seja, a medida em que se trabalha, planeja e realiza as atividades, o acadêmico tem a oportunidade de pensar o espaço em que está inserido. Essa inserção o permite vivenciar a prática e saber se naquele determinado lugar reside sua satisfação enquanto professor.

Desse modo, estar inserido nessa proposta, além de contribuir para a formação profissional, também traz contribuições para a formação pessoal. $\mathrm{O}$ acadêmico bolsista do programa, tem a oportunidade de reconhecer os espaços que tem mais afinidade para trabalhar, além de desenvolver a compreensão do trabalho em equipe, e de valorizar as experiências dos colegas de profissão e também dos próprios alunos.

\section{CONCLUSÃO}

Através da pesquisa realizada foi possível apontar a importância do Pibid para a formação inicial dos bolsistas participantes e também as contribuições do Curso de Magistério Saberes Pedagógicos, Criciúma, v. 3, n³, Edição Especial 2019.- Curso de Pedagogia - UNESC 
para essa formação, tendo em vista que as experiências vivenciadas ao longo da formação acadêmica influenciam na escolha do campo de atuação profissional. Assim, foram respondidos os objetivos específicos e as questões norteadoras.

O objetivo dessa pesquisa foi apontar as influências do Pibid/Subprojeto Interdisciplinar no Curso de Magistério, concluindo que o programa tem influenciado os bolsistas na escolha do campo de atuação. Contudo, concluiu-se que o programa não exerce uma forte influência sobre a escolha profissional, pois dentre os cinco entrevistados somente dois revelam a intenção de trabalhar com adultos, seja no Magistério, EJA ou Gestão Escolar. Outros dois afirmam o desejo de trabalhar na Educação Infantil, e um afirma a vontade de trabalhar em alguma área diferente, que exemplifica como uma brinquedoteca, um espaço lúdico ou na área da Educação Especial.

É importante ressaltar que através da pesquisa é possível valorizar o discurso desses profissionais em formação, dando voz as experiências que adquiriram ao longo da atuação nesse projeto. Durante as entrevistas, em cada resposta, ficou evidente a satisfação dos acadêmicos em participar de uma proposta que tem sido referência no meio acadêmico.

Este estudo contribui para minha formação no sentido de trazer questões da formação docente que são importantes para construir a identidade do professor. É também satisfatória por permitir que se explore e externe as contribuições deste projeto que agregou conhecimentos em minha trajetória acadêmica.

É claro que as conclusões e respostas obtidas aqui não se esgotam, pois o conhecimento se constrói diariamente, e a identidade dos professores também. Sugere-se então uma pesquisa com o coordenador do Pibid, com o professor supervisor e gestores do Curso de Magistério visando apontar as contribuições que o programa proporciona à formação docente.

\section{REFERÊNCIAS:}

AMBROSETTI, Neusa Banhara et al. Contribuições do PIBID para a formação

inicial de professores: o olhar dos estudantes. Educação em perspectiva, Viçosa. v. 4, n. 1, p. 151-174, jan./jun. 2013. Disponível em:

http://www.seer.ufv.br/seer/educacaoemperspectiva/index.php/ppgeufv/article/view/405/106

Saberes Pedagógicos, Criciúma, v. 3, n³, Edição Especial 2019.- Curso de Pedagogia - UNESC 


\section{SABERES PEDAGÓGICOS}

Revista do Curso de Graduaçūo de Pedagogia - Unesc

ISSN 2526-4559

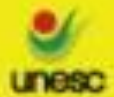

thisions

Acesso em: 25 fev. 2018.

ARANHA, Maria Lúcia de Arruda. História da educação e da pedagogia: Geral e Brasil. 3 ed. rev e ampl. SP: Moderna, 2006.

BRASIL. Conselho Nacional de Educação. Diretrizes Curriculares Nacionais para a formação de Professores na Modalidade Normal em Nível Médio. Câmara de Educação Básica - Brasília. 1999. Disponível em:

http://portal.mec.gov.br/dmdocuments/pceb001_99.pdf Acesso em: 14 maio 2018.

. Decreto no 7.219, de 24 de junho de 2010. Dispõe sobre o Programa Institucional de Bolsa de Iniciação à Docência - PIBID e dá outras providências. Diário Oficial da União. Brasília: Casa Civil da Presidência da República, 2010. Disponível em:

http://www.planalto.gov.br/ccivil_03/_ato2007-2010/2010/decreto/d7219.htm Acesso em: 27 fev. 2018.

Diretrizes Curriculares Nacionais para o Curso de Graduação em Pedagogia, Licenciatura, 2006. Disponível em: < http://portal.mec.gov.br/cne/arquivos/pdf/rcp01_06.pdf> Acesso em: 24 mar. 2018.

GARCÍA, Carlos Marcelo. Formação de professores: Para uma mudança educativa. Porto Editora: Portugal. 1999.

GIL, Antônio Carlos. Métodos e técnicas de pesquisa social. 4. ed. São Paulo: Atlas, 2008.

LIBÂNEO, José Carlos. Formação de Professores e Didática para Desenvolvimento Humano. Educação \& Realidade, [s.1.], v. 40, n. 2, p.629-650, 20 mar. 2015. Disponível em: http://www.scielo.br/pdf/edreal/2015nahead/2175-6236-edreal-46132.pdf Acesso em: 01 mar. 2018.

NÓVOA, António. Formação de Professores e profissão docente. 1992. Disponível: https://core.ac.uk/download/pdf/12424596.pdf Acesso em: 15 abr. 2018

NÓVOA, António. Para uma formação de professores construída dentro da profissão. Portugal, 2009. Disponível em:

http://www.revistaeducacion.educacion.es/re350/re350_09por.pdf Acesso em: 05 mar. 2018.

PINHEIRO, José Maurício dos Santos. Da iniciação científica ao TCC: uma abordagem para os cursos de tecnologia. Rio de Janeiro: Editora Ciência Moderna LTDA. 2010.

SOCZEK, Daniel. PIBID como Formação de Professores: reflexões e considerações preliminares. Revista Brasileira de Pesquisa sobre Formação Docente, Belo Horizonte, v. 03, n. 05, p. 57-69, ago./dez. 2011.

Disponível em http://formacaodocente.autenticaeditora.com.br. Acesso em: 18 maio 2018

Saberes Pedagógicos, Criciúma, v. 3, nº3, Edição Especial 2019.- Curso de Pedagogia - UNESC 
TARDIF, Maurice. Saberes docentes e formação profissional. Petrópolis, RJ: Vozes, 2002. TARDIF, Maurice. Saberes profissionais dos professores e conhecimentos universitários: elementos para uma epistemologia da prática profissional dos professores e suas consequências em relação à formação para o magistério. Revista Brasileira de Educação, $n^{\circ}$. 13, 2000. Disponível em:

http://anped.tempsite.ws/novo_portal/rbe/rbedigital/RBDE13/RBDE13_05_MAURICE_TAR DIF.pdf Acesso em: 18 maio 2018.

Recebido: 13/06/2019 